\title{
Electron probe microanalysis of the ultralight metal of beryllium
}

\section{Can Rao}

Key Laboratory of Geoscience Big Data and Deep Resource of Zhejiang Province, School of Earth Sciences, Zhejiang University, Hangzhou 310027, China. E-mail:canrao@zju.edu.cn

Beryllium (Be), known as one of the "strategic key metals", has been widely used in strategic emerging industries due to its unique physical and chemical properties. However, it's very difficult to analyze Be accurately in-situ in earth science and material science. In this experiment, we systematically, qualitative and quantitative analyzed Be by Shimadzu electron probe (EPMA-1720H). The best analytical conditions of beryllium are: $12 \mathrm{kV}$ voltage, 100-200 nA analytical current for anhydrous beryllium minerals, 50-100 nA analytical current for hydrous beryllium minerals, and with the pulse height analyzer (PHA). By these analytical conditions, we quantitatively analyze the the main Be-bearing minerals from beryllium resources, such as bertrandite, phenakite and beryl, and obtained a series of good analytical data. The contents of $\mathrm{BeO}$ in bertrandite range from 39.95 to $43.15 \mathrm{wt} \%$, and 45.33 to 47.08 wt. \% in phenakite from the volcanic rocks of Qingtian, Zhejiang Province. Beryl from the tungsten beryllium ore of Damingshan, Lin'an, Zhejiang Province contains 13.11-13.91 wt. \% BeO. The technical difficulties in quantitative analysis of beryllium, mainly include the flat shape of X-ray peak, low intensity and right shift of peak. The quantitative analysis of beryllium is not only of great practical significance to understand the occurrence, metallogenic mechanism and resource distribution of beryllium, but also helpful to reveal the mineralogical and geochemical properties of beryllium. 